\title{
Dual Energy CT Myelography after Lumbar Osteosynthesis
}

\section{Dual Energy Myelografie nach lumbaler Osteosynthese}

Authors

Affiliations
A. E. Grams ${ }^{1}$, J. Sender ${ }^{2}$, R. Moritz ${ }^{3}$, M. Obert ${ }^{2}$, M. Stein ${ }^{4}$, M. Oertel ${ }^{5}$, G. A. Krombach ${ }^{3}$, E. R. Gizewski ${ }^{1}$, T. Schmidt ${ }^{6}$

Affiliation addresses are listed at the end of the article.

\section{Key words \\ - spine \\ - $\mathrm{CT}$ \\ - surgery}

received $\quad 7.7 .2013$

accepted $\quad 24.10 .2013$

Bibliography

Dol http://dx.doi.org/

10.1055/s-0033-1356199

Published online: 4.2.2014

Fortschr Röntgenstr 2014; 186: 670-674 @ Georg Thieme

Verlag KG Stuttgart · New York . ISSN 1438-9029

\section{Correspondence}

Dr. Astrid Ellen Grams

Universitätsklinik für

Neuroradiologie, Medizinische

Universität Innsbruck

Anichstr. 35

6020 Innsbruck

Austria

Tel.: +43/05 12/50427095

Fax: $+43 / 0512 / 50427096$

astrid.grams@i-med.ac.at

\section{Zusammenfassung \\ $\nabla$}

Ziel: Das Ziel dieser Studie war es den Nutzen der CT-Myelografie in DE-Technik bei Patienten nach lumbaler Osteosynthese zu untersuchen.

Material und Methoden: Bei 30 Patienten wurde nach intrathekaler Gabe von Kontrastmittel eine DE-CT-Untersuchung der Lendenwirbelsäule mit Röhrenspannungen von $80 \mathrm{kV}$ und $140 \mathrm{kV}$ durchgeführt und eine virtuelle, monochromatische Serie von $120 \mathrm{kV}$ generiert. Es wurde der Einfluss von Metallartefakten auf den Spinalkanal und die Neuroforamina beurteilt und die Darstellung der Wurzeltaschen zwischen einer VRT-Serie und konventionellen Röntgenaufnahmen verglichen.

Ergebnisse: Mit Röhrenspannungen von $140 \mathrm{kV}$ waren die Artefakte am wenigsten stark ausgeprägt. Mit der VRT-Darstellung war es im Gegensatz zu den konventionellen Aufnahmen möglich die Wurzeltaschen ohne Überlagerung durch das Osteosynthesematerial darzustellen.

Schlussfolgerung: Bei Patienten mit lumbaler Osteosynthese erhält man im Rahmen der DE-CT mit $140 \mathrm{kV}$ einen nur minimal durch Artefakte überlagerten Datensatz. Die „virtuelle Myelografie“ mittels VRT-Rekonstruktionen scheint vorteilhaft gegenüber der konventionellen Myelografie bezüglich der Darstellung der spinalen Wurzeltaschen. Dies könnte zusätzliche konventionelle Aufnahmen und somit die Untersuchungs- und Durchleuchtungszeit reduzieren sowie unnötige, schmerzhafte Bewegungen für den Patienten vermeiden.

Kernaussage: Die DE-CT-Myelografie stellt eine vielversprechende Methode bei Patienten nach spinaler Osteosynthese dar.

\section{Introduction}

Degenerative spine disease often causes multifocal symptoms which may lead to frequent ima-

\section{Abstract \\ $\nabla$}

Purpose: The purpose of this study was to evaluate the benefits of CT myelography in the DE technique in patients with lumbar osteosynthesis.

Materials and Methods: In 30 patients a DE-CT scan of the spine with tube voltages of $80 \mathrm{kV}$ and $140 \mathrm{kV}$ was performed and a virtual monochromatic series of $120 \mathrm{kV}$ was generated after intrathecal contrast injection. The impact of metal artifacts on the spinal canal and the spinal foramina was evaluated. The visualization of nerve roots was compared between a VRT series of the dural sac and conventional myelography.

Results: With tube voltages of $140 \mathrm{kV}$, the artifacts were least pronounced. As no overlay disturbance was present, VRT visualization of the nerve roots was more reliable than conventional myelography.

Conclusion: In patients after osteosynthesis, CT in the DE technique provides minimal artifact disturbance using a tube voltage of $140 \mathrm{kV}$. "Virtual myelography" seems to be superior to conventional myelography for the evaluation of nerve roots. This could reduce additional conventional radiography, may shorten the entire examination and radiation time and diminish unnecessary painful movements for the patient.

Key Points: DE-CT myelography is a promising method in patients after spinal osteosynthesis.

Citation Format:

- Grams AE, Sender J, Moritz R et al. Dual Energy CT Myelography after Lumbar Osteosynthesis. Fortschr Röntgenstr 2014; 186: 670-674

ging. Magnetic resonance imaging may not be a reasonable alternative in patients with prior osteosynthesis due to the susceptibility to artifact disturbance [1]. This can lead to repeated CT ima- 
ging with resulting radiation exposure or myelography examinations with many projections.

Dual energy CT (DE-CT) allows either a reduction of the radiation dose with a comparable signal-to-noise ratio (SNR) or an increase of the SNR with a similar dose in comparison to single-energy (SE) acquisitions [2, 3]. In DE-CT two X-ray tubes with different tube voltages rotate simultaneously. This technique allows an almost simultaneous and fast image acquisition with the opportunity to reduce movement artifacts [4]. Additionally a reduction of beam hardening artifacts was described [5-9], which leads to a higher image quality especially in patients with prior osteosynthesis. The different absorptions of X-rays in DE-CT $[10,11]$ makes discrimination between different tissues possible [12]. Using appropriate software, tissue which is not of interest can be removed $[11,13]$. Therefore, it is possible to generate a "virtual" myelography from the original dataset using the volume rendering technique (VRT).

The aim of the current study was to evaluate the different DE-CT datasets with respect to artifact disturbance and to compare VRT myelography with conventional myelography regarding nerve root delineation.

\section{Materials and Methods:}

\section{$\nabla$}

\section{Study population}

This study was approved by the local ethics committee. Imaging data of 30 patients (19 female, 11 male) age $32-81$ years (mean 63 years) who had received prior lumbar pedicle screw fixation or disc replacements was included and evaluated retrospectively. Depending on the previous surgery and existing osteosynthesis material, different numbers of lumbar levels were assessed. In all cases the indication for imaging was persistent or new radicular complaints with or without back pain.

\section{Myelography and dual energy CT}

After intrathecal injection of iodine contrast agent (10 ml Solutrast $250 \mathrm{M}^{\circledR}$, Bracco Altana Pharma, Konstanz, Germany), the patients underwent X-ray imaging including lateral, anterior-posterior, and left/right oblique views. Lumbar spine CT imaging was performed with a DE scanner (Somatom Definition, Siemens, Erlangen, Germany) with tube voltages of $140 \mathrm{kV}$ and $80 \mathrm{kV}(\mathrm{kV} /$ $\mathrm{mAS}=140 / 86$ and $80 / 468$, FOV=167, collimation $=14 \times 1.2$, pitch $=0.55$ ). The computed tomography dose index (CTDI) of the entire scan was $17.49 \mathrm{mGy}$.

\section{Post-processing}

In addition, a virtual monochromatic $120 \mathrm{kV}$ series with a ratio of 0.3 (70\% of the information from the $140 \mathrm{kV}$ dataset and $30 \%$ from the $80 \mathrm{kV}$ dataset) was generated. The data was reconstruc- ted with a slice thickness of $1.5 \mathrm{~mm}$, an increment of $1.0 \mathrm{~mm}$, a medium sharp kernel (D50f) at a level of $400 \mathrm{HE}$ and a center of 70 HE. In post-processing a $3 \mathrm{D}$ dataset of each tube voltage was archived and virtual myelography VRT datasets were generated using the software component "dual energy, body bone removal" (syngo MMWP, VE 32B, Siemens, Erlangen, Germany) in lateral, anterior-posterior, and two oblique views $\left(45^{\circ}\right)$ comparable to the conventional data.

\section{Artifact evaluation and statistical analysis}

The evaluation of artifacts according to the visualization of the spinal canal and the foramina was performed with a four-point evaluation scale in consensus by two experienced radiologists. 77 lumbar levels were included for the evaluation of the spinal canal and 66 for the evaluation of the spinal foramina. Each dataset was evaluated in a three-dimensional view parallel to the intervertebral disc. For statistical evaluation a Friedman test was applied (StatView, SAS Institute Inc.@, Version 5.0.1). Statistical differences with an error probability of $\mathrm{p}<0.05$ were accepted as significant.

\section{Comparison of VRT and myelography}

Data of 202 lumbar spinal nerve roots in anterior-posterior views and 197 roots in oblique views was included. The VRT dataset was compared to the conventional myelography with respect to the visualization of the roots in healthy and in fused levels by counting the number of visible roots for each modality.

\section{Results: \\ $\nabla$}

\section{Artifact evaluation}

The results of the four-point artifact evaluations are given in numeric data in Table 1. With tube voltages of $140 \mathrm{kV}$, the beam hardening artifacts were least pronounced. With this voltage most evaluated levels were only slightly disturbed by artifacts concerning the spinal canal as well as the spinal foramina. In comparison to the other tube voltages with this voltage most levels with "no artifact disturbance" could be found. Artifact disturbance was either slight or moderate in more than $50 \%$ of the evaluated levels in the spinal canal ( $\bullet$ Fig. 1a). The imaging quality was somewhat worse in the spinal foramina ( 0 Fig. 2a). In the $80 \mathrm{kV}$ series artifacts limited the evaluation severely in most levels of the spinal canal ( $\bullet$ Fig. 1b) and the spinal foramina ( Fig. 2b), for both areas in more than $50 \%$ of the evaluated levels. In the evaluation of the virtual monochromatic $120 \mathrm{kV}$ series ( $\bullet$ Fig. 1c, 2c), a moderately disturbed imaging quality for most levels was found in the evaluation of the spinal canal. By evaluating the spinal foramina, almost the same number of levels was slightly, moderately or severely disturbed by artifacts. All these differences were statistically significant $(p<0.0001)$.

Table 1 Consensus evaluation of artifact disturbance in the spinal canal and the spinal foramina with different tube voltages and the virtual series with number of levels assigned for each scale point.

\begin{tabular}{|c|c|c|c|c|c|c|c|c|c|c|c|c|c|}
\hline \multirow{2}{*}{$\begin{array}{l}\text { Tube voltage } \\
\text { 4-point scale }\end{array}$} & & \multicolumn{4}{|c|}{$140 \mathrm{kV}$} & \multicolumn{4}{|c|}{$80 \mathrm{kV}$} & \multicolumn{4}{|c|}{$120 \mathrm{kV}$} \\
\hline & & 0 & 1 & 2 & 3 & 0 & 1 & 2 & 3 & 0 & 1 & 2 & 3 \\
\hline spinal canal & number of levels $(n=77)$ & 6 & 28 & 23 & 20 & 0 & 6 & 17 & 54 & 0 & 18 & 33 & 26 \\
\hline spinal foramina & number of levels $(n=66)$ & 11 & 23 & 16 & 16 & 1 & 10 & 14 & 41 & 7 & 20 & 19 & 20 \\
\hline
\end{tabular}

Criteria: no artifacts $=0$, artifacts with slight disturbance $=1$, artifacts with moderate disturbance $=2$, artifacts with severe disturbance $=3$. 

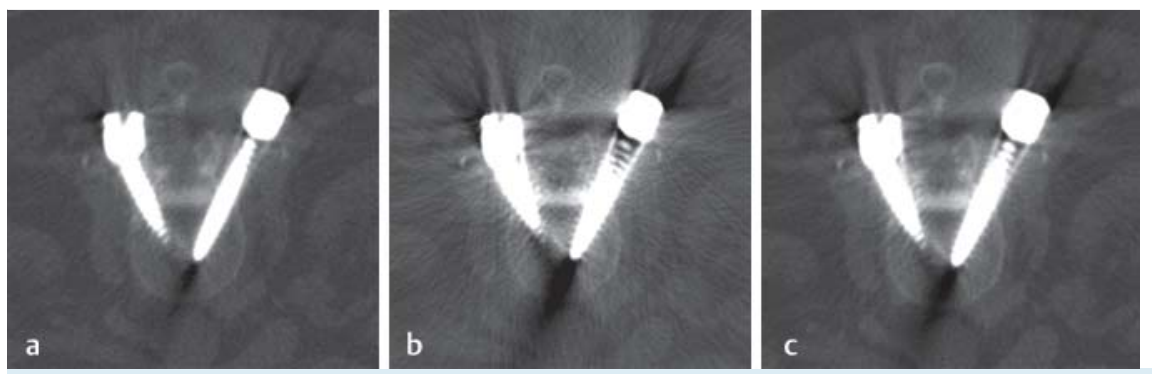

Fig. 1 Axial views of the spinal canal with $140 \mathrm{kV}$ a, $80 \mathrm{kV}$ b and the virtual $120 \mathrm{kV}$ series $\mathrm{c}$. In this example beam hardening artifacts lead to a slight disturbance in the $140 \mathrm{kV}$ series, a severe disturbance in the $80 \mathrm{kV}$ series and a moderate disturbance in the virtual series.

Abb. 1 Axiale Darstellung des Spinalkanals mit 140 kV a, 80 kV b und der virtuellen 120 kV c Serie. In diesem Beispiel führen Aufhärtungsartefakte zu einer geringen Einschränkung in der 140 kV Serie, zu einer deutlichen in der 80 kV Serie und einer moderaten in der virtuellen Serie.
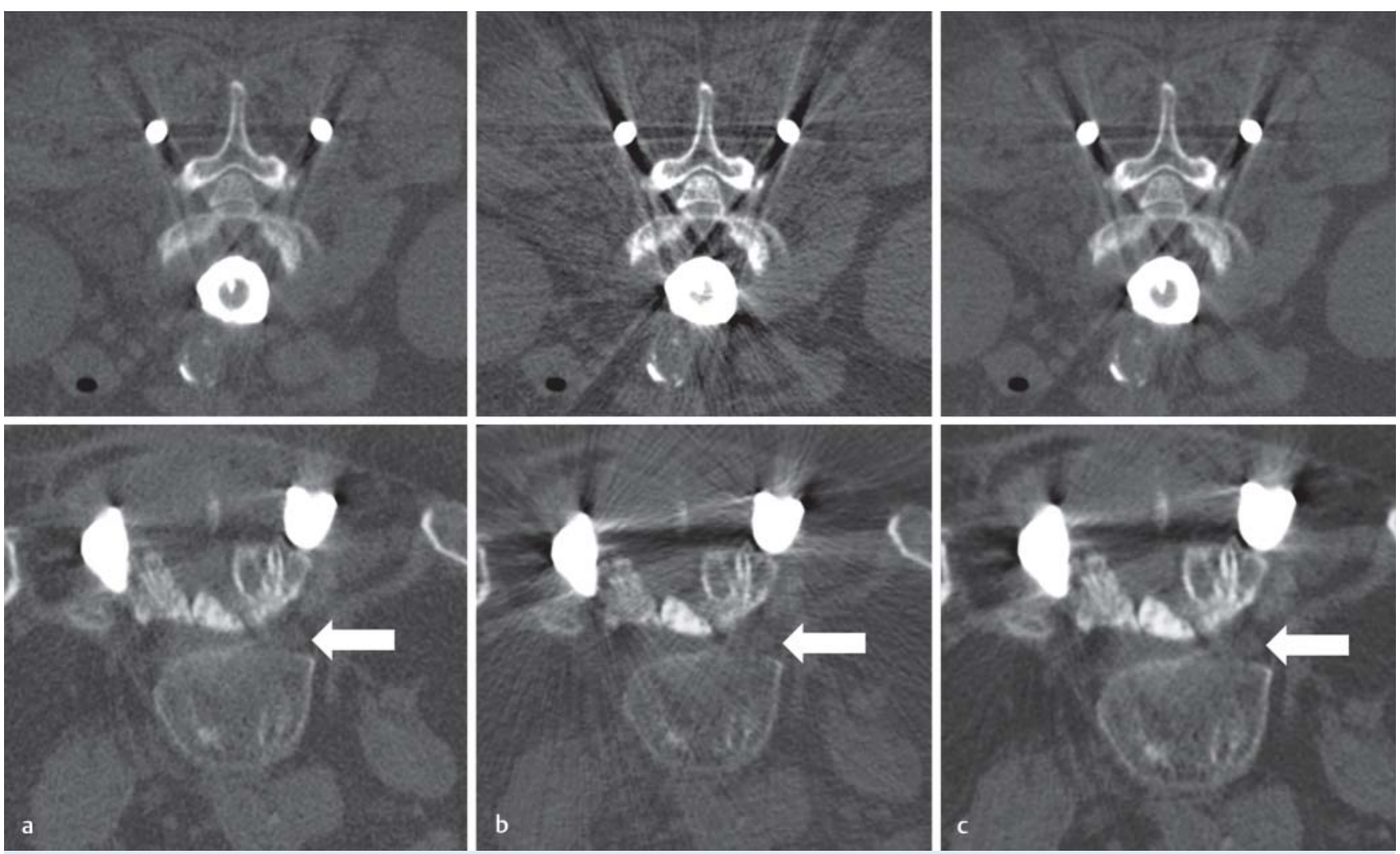

Fig. 2 Axial views of the spinal foramina with $140 \mathrm{kV}$ a, $80 \mathrm{kV}$ b and the virtual $120 \mathrm{kV}$ series $\mathbf{c}$ in two different patients. Arrows are pointing to the nerve roots. In this example beam hardening artifacts lead to no disturbance in the $140 \mathrm{kV}$ series, a severe disturbance in the $80 \mathrm{kV}$ series and a slight disturbance in the virtual series.

Abb. 2 Axiale Darstellung der Neuroforamina mit $140 \mathrm{kV} \mathrm{a}, 80 \mathrm{kV}$ b und der virtuellen 120 kV c Serie bei zwei verschiedenen Patienten. Die Pfeile zeigen auf die Spinalnerven. In diesem Beispiel führen die Aufhärtungsartefakte zu keiner Einschränkung in der $140 \mathrm{kV}$ Serie, zu einer deutlichen in der $80 \mathrm{kV}$ Serie und einer geringen in der virtuellen Serie.

\section{Comparison of VRT and conventional myelography}

In an anterior-posterior view, 162 of 202 (80\%) roots were seen with VRT and 110 of 202 (55\%) with conventional myelography (॰ Fig. 3 a-c). In oblique views 161 of 197 (82\%) roots were displayed with VRT and 96 of 197 (49\%) with conventional myelography. Due to the opportunity of material removal in VRT, no overlay problems were present, whereas in conventional myelography overlay from intervertebral material in the anterior-posterior view and from the fixateur interne in the oblique views was seen.

\section{Discussion}

$\nabla$

In the present setting a low CTDI of $17.49 \mathrm{mGy}$ could be achieved with DE-CT lumbar spine imaging. In phantom studies and in other organ systems than the spine, a reduction of dose while maintaining a comparable SNR was described by comparing the $120 \mathrm{kV}$ virtual monochromatic DE series and $120 \mathrm{kV}$ SE images $[2,3,6]$. This was explained by the fact that with an increasing tube voltage, the SNR increases and the tissue contrast decreases, whereas lowering the tube voltage leads to an increased tissue contrast and a decreased SNR. DE imaging is supposed to combine these advantages $[2,14]$. It can either be used for dose re- 

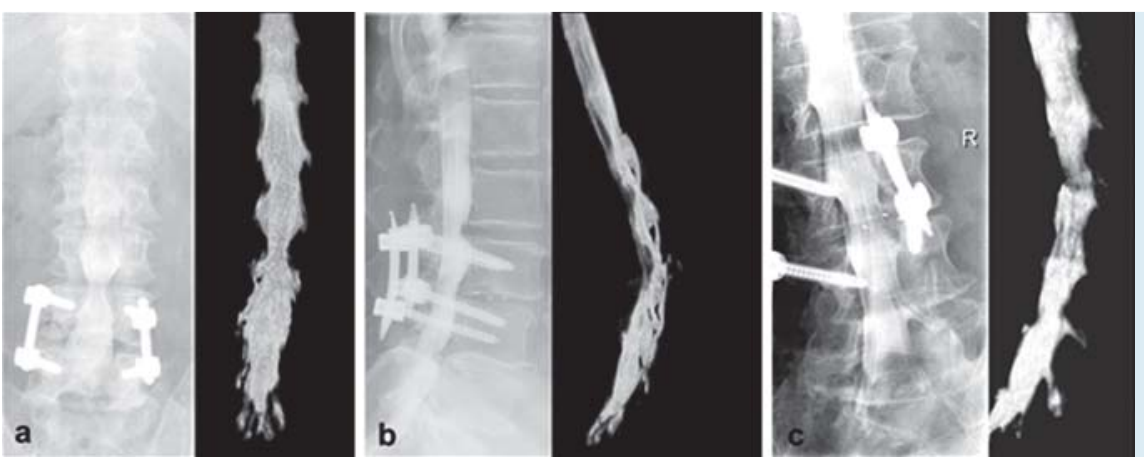

Fig. 3 Conventional myelography and DE-VRT in anterior posterior $\mathbf{a}$, lateral $\mathbf{b}$ and oblique $\mathbf{c}$ views.

Abb. 3 Konventionelle Myelografie und DE-VRT in anterior-posterior $\mathbf{a}$, lateraler $\mathbf{b}$ und schräger c Darstellung.

duction while maintaining a similar SNR compared to SE imaging or to increase the SNR with a comparable dose to SE imaging [2, 3]. A limitation of the present study is that DE and SE CT myelography studies have not been compared concerning dose radiation, which could represent a topic for another study. As the existing studies in several other organ systems comparing both techniques show a similar or even better SNR [13, 15-17], this was transferred to the spine.

In the present study the default ratio of $0.3(12 \mathrm{kV})$ for the virtual monochromatic series was applied, which was shown to exhibit a similar SNR compared to SE in the central SNR [3]. In several other studies other ratios were described to provide a further increase of imaging quality [18].

In the present study it was shown that beam hardening artifacts are less with tube voltages of $140 \mathrm{kV}$ than with $80 \mathrm{kV}$ or the virtual monochromatic $120 \mathrm{kV}$ series. This is in accordance with earlier studies about the evaluation of intracranial aneurysm clips $[5,19]$ or metal implants in different body regions [20]. In the last mentioned study additional high voltage interpolation postprocessing from DE data lead to a further decrease in artifacts. Post-processing modifications were not the focus in the present study. With monoenergetic extrapolation of DE data, a reduction of beam hardening artifacts from implants could be achieved, in comparison to single energy acquisition [7, 8]. However, in the present study the monochromatic evaluation of $140 \mathrm{kV}$ led to evaluation of the spinal canal and the spinal foramina with minimal artifact disturbance. The $80 \mathrm{kV}$ series could display advantages in areas where artifact disturbance does not play a role but a high contrast might be helpful such as in searching for CSF leakages. Modification of the monochromatic series was not the topic of the present study but could represent a topic for further investigation.

Virtual myelography showed marked advantages in comparison to conventional myelography as overlay problems of the fixateur interne in the oblique view and of intervertebral material in the anterior-posterior view are not present. This post-processing step reveals the opportunity to shorten conventional imaging with shortened radiation exposure for patients and fewer painful movements. In addition, the radiation exposure for the radiologist or technician, who is in the room during data acquisition, is reduced as well. However, DE VRT cannot replace dynamic conventional studies in patients with adjacent level instability. In the present study functional conventional imaging was only performed in some individuals in whom instability was assumed. In patients who do not need functional conventional imaging, conventional imaging could be dispensed with.

There are some limitations concerning the imaging evaluation in this study: the applied four-level scale for the consensus evalua- tion of artifacts is a common method for comparing imaging data $[5,20]$ but it is a subjective approach. In counting spinal roots in conventional imaging and VRT myelography, no reviewer blinding concerning the methods was possible since the images revealed the technique.

In conclusion, DE-CT myelography can be an opportunity to reduce dose, depending on the designated imaging quality. The minimization of artifact disturbance due to a high tube voltage and the possibility of "virtual" myelography are significant advantages in patients with prior osteosynthesis. The presented new methodology may partly replace conventional imaging because no overlay disturbance from osteosynthesis material is present.

\section{Clinical relevance:}

\section{$\nabla$}

- DE CT myelography can be a tool for dose reduction.

- DE CT myelography combines high contrast imaging and minimal artifact disturbance.

- DE "virtual myelography" is advantageous after osteosynthesis in comparison to conventional myelography for the evaluation of spinal nerve roots.

- DE "virtual myelography" can partly replace extensive X-ray examinations in conventional myelography.

\section{Affiliations \\ Department of Neuroradiology, Medical University Innsbruck \\ 2 Department of Neuroradiology, University Hospital Giessen \\ Department of Radiology, University Hospital Giessen \\ 4 Department of Neurosurgery, University Hospital Giessen \\ 5 Department of Neurosurgery, Vogtland-Klinikum Plauen \\ Department of Neuroradiology, Klinikum Wuppertal}

\section{References:}

1 Knott PT, Mardjetko SM, Kim RH et al. A comparison of magnetic and radiographic imaging artifact after using three types of metal rods: stainless steel, titanium, and vitallium. The spine journal : official journal of the North American Spine Society 2010; 10: 789-794

2 Bauer RW, Kramer S, Renker $M$ et al. Dose and image quality at CT pulmonary angiography-comparison of first and second generation dualenergy CT and 64-slice CT. Eur Radiol 2011; 21: 2139-2147

3 Thomas C, Ketelsen D, Tsiflikas I et al. Dual-energy computed tomography: is there a penalty in image quality and radiation dose compared with single-energy computed tomography? J Comput Assist Tomogr 2010; 34: 309-315

4 Flohr TG, McCollough CH, Bruder $\mathrm{H}$ et al. First performance evaluation of a dual-source CT (DSCT) system. Eur Radiol 2006; 16: 256-268 
5 Fahrendorf DM, Goericke SL, Oezkan $N$ et al. The value of dual-energy CTA for control of surgically clipped aneurysms. Eur Radiol 2011; 21: $2193-2201$

6 Schenzle JC, Sommer WH, Neumaier K et al. Dual energy CT of the chest: how about the dose? Investigative radiology 2010; 45: 347-353

7 Zhou C, Zhao YE, Luo S et al. Monoenergetic imaging of dual-energy CT reduces artifacts from implanted metal orthopedic devices in patients with factures. Acad Radiol 2011; 18: 1252 - 1257

8 Guggenberger R, Winklhofer S, Osterhoff G et al. Metallic artefact reduction with monoenergetic dual-energy CT: systematic ex vivo evaluation of posterior spinal fusion implants from various vendors and different spine levels. European radiology 2012; 22: 2357-2364

9 Stolzmann P, Winklhofer S, Schwendener N et al. Monoenergetic computed tomography reconstructions reduce beam hardening artifacts from dental restorations. Forensic science, medicine, and pathology 2013; DOI: 10.1007/s12024-013-9420-z

10 Lell MM, Kramer M, Klotz E et al. Carotid computed tomography angiography with automated bone suppression: a comparative study between dual energy and bone subtraction techniques. Investigative radiology 2009; 44: 322-328

11 Thomas C, Korn A, Krauss B et al. Automatic bone and plaque removal using dual energy CT for head and neck angiography: feasibility and initial performance evaluation. Eur J Radiol 2010; 76: 61 -67

12 Johnson TR, Krauss B, Sedlmair M et al. Material differentiation by dual energy CT: initial experience. Eur Radiol 2007; 17: 1510-1517

13 Morhard D, Fink C, Graser A et al. Cervical and cranial computed tomographic angiography with automated bone removal: dual energy com- puted tomography versus standard computed tomography. Investigative radiology 2009; 44: $293-297$

14 Wintermark M, Maeder P, Verdun FR et al. Using $80 \mathrm{kVp}$ versus $120 \mathrm{kVp}$ in perfusion $\mathrm{CT}$ measurement of regional cerebral blood flow. AJNR Am J Neuroradiol 2000; 21: 1881 - 1884

15 Hwang HJ, Seo JB, Lee JS et al. Radiation dose reduction of chest CT with iterative reconstruction in image space - Part II: assessment of radiologists' preferences using dual source CT. Korean journal of radiology: official journal of the Korean Radiological Society 2012; 13: 720-727

16 Mayo J, Thakur Y. Pulmonary CT angiography as first-line imaging for PE: image quality and radiation dose considerations. Am J Roentgenol American journal of roentgenology 2013; 200: 522-528

17 Gervaise A, Teixeira P, Villani $N$ et al. CT dose optimisation and reduction in osteoarticular disease. Diagnostic and interventional imaging 2013; 94: 371 - 388

18 Paul J, Bauer RW, Maentele W et al. Image fusion in dual energy computed tomography for detection of various anatomic structures-effect on contrast enhancement, contrast-to-noise ratio, signal-to-noise ratio and image quality. Eur J Radiol 2011; 80: 612 -619

19 van der Schaaf I, van Leeuwen M, Vlassenbroek $A$ et al. Minimizing clip artifacts in multi CT angiography of clipped patients. AJNR Am J Neuroradiol 2006; 27: 60-66

20 Bamberg F, Dierks A, Nikolaou K et al. Metal artifact reduction by dual energy computed tomography using monoenergetic extrapolation. Eur Radiol 2011; 21: 1424-1429 